\title{
Research on the material degradation model and the bonding-slipping effect of reinforced concrete
}

\author{
Jian Shen ${ }^{1, a}$, Xiaoyun Liư \\ ${ }^{1}$ School of Civil Engineering and Architecture, Jiangxi Science \& Technology Normal University, \\ Fenglin Avenue 605\#, Nanchang, Jiangxi P.R.China 330013 \\ ${ }^{2}$ School of foreign languages, Jiangxi Science \& Technology Normal University, Fenglin Avenue \\ 605\#, Nanchang, Jiangxi P.R.China 330013 \\ a894282069@qq.com, b505132338@qq.com
}

Key words: reinforced concrete, bonding-slipping effect, corrosion

Abstract: Based on the modified plate-truss model, the time-varying ultimate capacity of RC subjected to bending, shear and torsion were studied. An average constitutional relationship of steel bar is developed by considering both the bonding-slipping effect and corrosion ratio of reinforcing steel bar. The calculation of time-varying bearing capacity is given by the introducing material degradation models in general environment.

\section{Introduction}

The reinforced concrete structures bearing capacity has the characteristics of time-varying in the whole life period. One of the most main influencing factors is the steel bar corrosion, which is adverse impact for both the structure service life and security. The durability problem of the reinforced concrete structures caused by corrosion, is mostly focused on the micro level materials or components, such as prediction of the reinforcement corrosion degree, protective layer expansion cracking mechanism, and the nonlinear behavior of force under the condition of single components and bearing capacity analysis, etc. On the other hand, the bond strength between steel bars and concrete will be lower and the bond-slip effect will be obviously, especially after the entrance of the corrosive cracks developing.

\section{Corroded steel bars constitutive relation}

Along with the increase of the corrosion degree, the steel bar yield strength, ultimate strength and ultimate strain will be decreased and the steel bar yield platform will also be shortened or disappeared, but the reduction of elastic modulus is not obvious. The three line stress-strain relationship is selected.

$$
\sigma_{s c}=\left\{\begin{array}{lc}
E_{s} \varepsilon_{s c} & \left(\varepsilon_{s c} \leq f_{y c} / E_{s}\right) \\
f_{y c} & \left(f_{y c} / E_{s}<\varepsilon_{s c} \leq \varepsilon_{s h c}\right) \\
f_{y c}+\left(\varepsilon_{s c}-\varepsilon_{s h c}\right)\left(f_{u c}-f_{y c}\right) /\left(\varepsilon_{s u c}-\varepsilon_{s h c}\right) & \left(\varepsilon_{s c}>f_{y c} / E_{s}\right)
\end{array}\right.
$$

$E_{s}$--steel bar elastic modulus, $f_{y c}$-- corroded steel bar yield strength, $f_{u c}$-- corroded steel bar

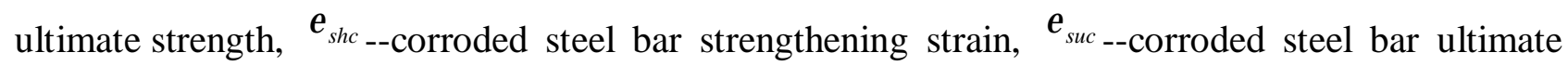


strain. Phase 1 of this formula is the elastic stage, the phase 2 for the yield stage and the phase 3 similar strengthening stage.

Based on the cracking reinforced concrete bond-slip theory, the fixed average stress-strain relationship of uniaxial tensile component is put forward with considering the effect of bond-slip reinforcement. In this article, a further reinforced concrete plane stress problem that the concrete cracking surface obliques with the steel bars situation is considered. The cracking reinforced modified average stress-strain relationship of concrete unit is put forward to analyze the reinforced concrete box girder bend-shear composite force.

With plane stress of reinforced concrete cracking unit, in the case of stirrup, it is assumed that stress is uniform distributed over both concrete and steel bars before cracking. After cracking, the stress of steel bars is maximum on the crack surface and the stress of concrete is zero and gradually tent to evenly distributed along the reinforcement direction. With the increase of crack width, crack surface steel bars stress is increased gradually and evenly distributed in the crack width scope. It is assumed that the crack width is the difference deformation between reinforcement and concrete. By the stirrup strain state, the crack width can be represented as:

$$
w=2 \int_{0}^{L / \cos \alpha}\left[\varepsilon_{s}(x)-\varepsilon_{c}(x)\right] d x \cdot \cos \alpha=2 \varepsilon_{s}(0) L-\frac{\pi d \tau_{m} L^{2}}{A_{s} E_{s} \cos \alpha}-\frac{n \pi d \tau_{m} L^{2}}{A_{c} E_{c} \cos \alpha}
$$

After cracking, half the length of the common reinforced concrete can be represented as:

$$
L_{1}=L+\int_{0}^{L / \cos } \frac{n \pi d \tau_{m} x}{A_{c} E_{c}} d x \cdot \cos \alpha=L+\frac{n \pi d \tau_{m} L^{2}}{2 A_{c} E_{c} \cos \alpha}
$$

A single average crack spacing within the scope of the stirrup stress can be represented as:

$$
\bar{\sigma}_{s 1}=\frac{\int_{0}^{L_{1} / \cos \alpha}\left(\sigma_{s}(0)-\frac{\pi d \tau_{m} x}{A_{s}}\right) d x}{L_{1} / \cos \alpha}=\sigma_{s}(0)-\frac{\pi d \tau_{m} L_{1}}{2 A_{s} \cos \alpha}
$$

The stirrup stress and strain within the scope $L_{1} / \cos \alpha+w / 2 \cos \alpha$ is shown as follows:

$$
\bar{\sigma}_{s}=\frac{\bar{\sigma}_{s 1} \frac{L_{1}}{\cos \alpha}+\sigma_{s}(0) \frac{w}{2 \cos \alpha}}{L_{1} / \cos \alpha+w / 2 \cos \alpha}, \quad \bar{\sigma}_{s}=\frac{\frac{\bar{\sigma}_{s 1}}{E_{s}} \frac{L_{1}}{\cos \alpha}+\varepsilon_{s}(0) \frac{w}{2 \cos \alpha}}{L_{1} / \cos \alpha+w / 2 \cos \alpha}
$$

\section{Fracture spacing and the choice of bond stress}

The correction calculation of steel bar stress - strain relationship is integration along the half crack spacing points. In addition to the steel yield strength and ultimate strength in the process of calculation, the clear mechanical parameters such as elastic modulus, the bond stress between steel bar and reinforced concrete and the diagonal crack spacing are also needed to know.

The cohesive force between steel bars and concrete is constantly changing with the stress and different in the direction of the reinforcement also. The cohesive force is increased with the corrosion reinforcement rust initially, but with the increase of the corrosion degree bond strength is significantly lower, especially after the corrosive cracking. The calculation coefficient is obtained by experiment of corroded deformed bars and concrete bonding effect to avoid considering the corrosive crack width and the bond strength.

$$
\eta_{b}=1+7.0 \eta_{s} \quad \eta_{s} \leq 5 \%, \quad \eta_{b}=1.46-2.3 \eta_{s} \quad \eta_{s}>5 \%
$$




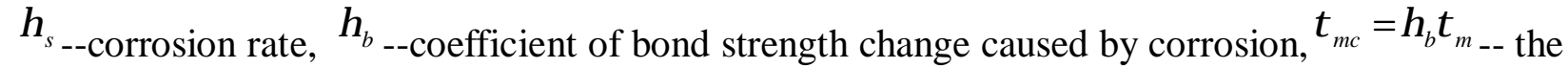
bond strength between concrete and steel bars after corrosive.

The concrete crack expansion experiences development and stability stages in general. The crack spacing in stable stage is constantly changed because the crack spacing accompanied by the emergence of new cracks before meeting the minimum crack spacing. According to reinforced concrete plane stress problem such as the equivalent calculation method, equivalent simplification is adopted to take concrete average crack spacing.

$$
l_{m}=1.5 f_{t} A_{c, e q} / n \tau_{m} \pi d_{e q}
$$

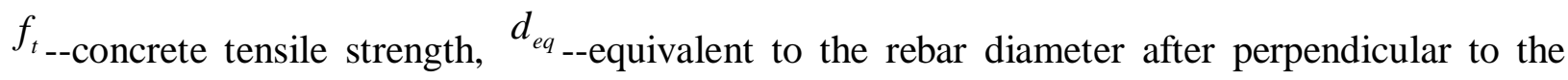
fracture plane, $A_{c, e q}=0.25 \pi d_{e q}^{2} / \rho_{r}$-- concrete equivalent tensile area, $\rho_{r}$ steel reinforcement equivalent ratio.

\section{The choice of material degradation model}

For general concrete structure under the atmosphere environment, the concrete compressive strength attenuation law can be adopted as the following expression.

$$
f_{c}(t)=1.4529 e^{-0.0246(\ln t-1.7154)^{2}} f_{c}(0)
$$

$f_{c}(t)$--the concrete compressive strength changing with time, $f_{c}(0)$--concrete 28-day strength.

It is assumed that the steel bars degradation is obeyed attenuation type and can be expressed with reinforcement corrosion depth.

$$
\delta(t)=0.0166 \times 1.9718 i_{0} t^{0.71}
$$

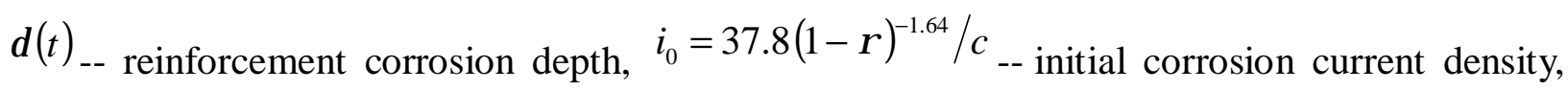

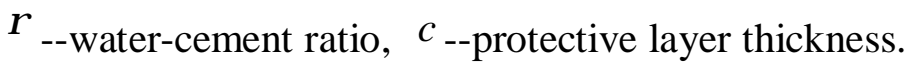

Reinforcement corrosion rate changing with time can be expressed as follow.

$$
\eta_{s}(t)=4 \delta(t) / d
$$

$d$--steel bar diameter.

The time prediction of steel bars corrosion is equally important as the bearing capacity of time-varying structure. The prediction formula in the average atmospheric environment is shown as follow.

$$
t_{c r}=\left(\frac{c-x_{0}}{k}\right)^{2}
$$

$k$--carbonation coefficient, the approximation is taken as 1.3 in this article. ${ }^{x_{0}}$--carbonated residue content. 


$$
x_{0}=\left(1.2-0.35 k^{0.5}\right) c-\frac{6}{k_{c e}+1.6}(1.5+0.84 k)
$$

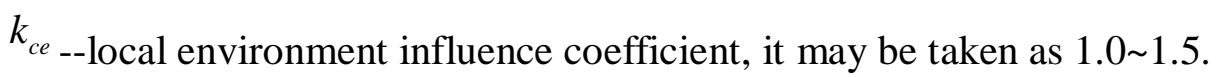

The reinforced concrete members under the above-mentioned complex mechanical state (considering material degradation, stirrup and longitudinal reinforcement corrosion and the change of the concrete strength) is meet the general truss strain coordination and balance condition theory also. The most obvious difference is obvious slip effect of reinforcement and concrete with the corrosion of steel bar. The material parameters must be fixed according to the different moment during the process to calculate the bearing capacity of composite.

\section{Conclusion}

An average constitutional relationship of steel bar is developed by considering both the bonding-slipping effect and corrosion ratio of steel bars.

The calculation flowchart of time-varying bearing capacity is given by the introducing material degradation models in general environment.

\section{Acknowledgments}

This research was supported by Dr. Scientific Research Startup Funds of Jiangxi Science \& Technology Normal University (3000990105), which is gratefully acknowledged.

\section{References:}

[1] Khan I, Francois R, Castel A. Prediction of reinforcement corrosion using corrosion induced cracks width in corroded reinforced concrete beams [J], Cement and Concrete Research, 2014, 56: 84-96.

[2] Bo Yu, LuFeng Yang, Ming Wu,et al. Practical model for predicting corrosion rate of steel reinforcement in concrete structures [J]. Construction and Building Materials, 2014, 54(15):385-401.

[3] Saad-Eldeen S, Garbatov Y, Soares C G Corrosion-dependent ultimate strength assessment of aged box girders based on experimental results [J]. Journal of Ship-Research, 2011, 55(4):289-300.

[4] Almusallam A A. Effect of corrosion on the properties of reinforcing steel bars [J].Construction and Building Materials, 2001, 15: 361-368.

[5] Hutchinson T C, Wang T. Evaluation of crack spacing in reinforced concrete shear walls [J].Journal of Structural Engineering, 2009, 135(5): 499-508. 